\title{
INTERNALLY WEIGHTED DENTURES: A TREATMENT MODALITY FOR SEVERELY RESORBED MANDIBULAR RIDGE: A CASE REPORT
}

\author{
Puja Hazari¹, Mukesh Yadav², Ajay Gaikwad³, Vandana Singh", Kirti Somkuwar
}

\section{HOW TO CITE THIS ARTICLE:}

Puja Hazari, Mukesh Yadav, Ajay Gaikwad, Vandana Singh, Kirti Somkuwar. "Internally Weighted Dentures: A Treatment Modality for Severely Resorbed Mandibular Ridge: A Case Report”. Journal of Evolution of Medical and Dental Sciences 2014; Vol. 3, Issue 41, September 04; Page: 10374-10378,

DOI: $10.14260 /$ jemds/2014/3347

ABSTRACT: Severe atrophy of the residual alveolar ridges poses a clinical challenge for successful prosthodontic rehabilitation. Extreme resorption of the ridge whether maxilla or mandible will lead to a reduced denture bearing area which in turn will affect retention, stability and support for the complete denture. The severely atrophied jaw can have various treatment options. For more than 150 years, it was believed that the weight of the lower denture contributes to both retention and stability. This concept of internally weighted denture suggested that gravity and the additional weight to the mandibular complete denture aids in prosthetic retention.

KEYWORDS: Internally weighted, Atrophy, rehabilitation, resorption, residual alveolar ridge.

INTRODUCTION: Most lower dentures weigh less than half as much as the teeth and supporting tissues which have been lost. This reduction in weight might contribute to improper muscle function and a reduction in normal vertical dimension at rest. It is considered to be an important factor in the adequate extension and retention in lower dentures, especially in certain types of residual ridges. These deficiencies can be overcome by using a cast lower denture base and adequate extension of the base. ${ }^{1}$

Grunewald introduced gold as the metal of choice for the resorbed mandibular residual ridge. He compared the weight of the average gold base with the weight of the teeth and bone lost through extraction and extensive resorption and suggested a gold base of approximately $16 \mathrm{dwt}(25 \mathrm{~g}) \mathrm{dwt}$ [Dead weight tonnage]. [20dwt $=31.104 \mathrm{gms}$ ] for the average-sized mandible. ${ }^{1,2}$

Belfiglio (1987) also advocated metal bases in making complete dentures when a high degree of processing change is expected, or when additional strength is needed. Significant disadvantages of metal base dentures are that they often irritate the underlying alveolar ridge and are difficult to reline and adjust. Massad introduced a metal base denture with a resilient liner to manage the severely resorbed mandibular residual ridge. ${ }^{2}$

Various techniques have been proposed for fabricating and positioning the internal metal bases during denture processing to overcome the disadvantage of the metal base. Wormley and Brunton described a technique to fabricate internally weighted mandibular dentures using chromecobalt alloy or gold. Softened sticks of wax were molded into a triangular cross-section shape directly from the definitive cast to fabricate a metalbar. ${ }^{3}$

Hurtado technique consisted of fabricating a weighted metal base made from a duplicated stone cast, and incorporated a wax spacer and 4 metal tissue stops.2,4 Obtaining consistent mandibular denture stability has long been a challenge for the dental profession. In particular a flat lower ridge is associated with difficulties in providing successful dentures. Hence a number of 
authors have advocated recording the neutral zone, and dynamic impression procedures to enhance stability, retention and comfort. 5

This article describes a method for fabricating an internally weighted mandibular complete denture using a cast metal insert in a processed denture base and neutral zone recording for tooth arrangement. The design and position of the metal base is customized for an optimal esthetic and functional outcome, and allows for conventional reline procedures.

CASE REPORT: A male patient, 62 years of age, visited the Department of Prosthodontics, Peoples College of dental sciences and research Centre, Bhopal. Chief complaints were the presence of two soft tissue growths in the lower vestibule. The dentures which were made 12 years back were non retentive and showed loss of stability.The teeth showed presence of severe attrition and loss of vertical dimension of occlusion. [Fig. 1a, 1b] Patient also gave history of undergoing orthognathic surgery for pre maxillary prominence, 35 years back.

There were two soft tissue growths in the lower anterior region [midline].Radiographic and clinical investigations were done. No bony component to the growth was detected. Also the growths were pedunculated with no signs of attachment to the bone. These growths were surgically excised.

After healing of the wound the patient was recalled for new denture fabrication. [Fig. 2a, 2b, 2c]] A full-coverage mucostatic mandibular impression was made by using stock impression trays and irreversible hydrocolloid (Tropicalgin, Zhermack, Italy), which was poured with type 3 dental stone (Denstone, Zhermack, Italy).

Self-cure acrylic resin template (Acralyn, Asian Acrylates, Mumbai, India) was made. Physiologic impression was made with soft liner using acrylic resin template as custom tray. (Fig. 3). The template was given for one week for functional remolding. This functional impression was then poured as the final cast. (Denstone, Zhermack,Italy).

The final cast was duplicated. On the duplicated cast two sheets of modeling wax were adopted. (Rolex, Ashoo Sons, New Delhi, India) One sheet was then cut and removed from the area which the metal casting would occupy, as described by Graser. ${ }^{6}$ [Fig. 4]

This assembly was then duplicated and a refractory cast was made. On the refractory cast a spacer wax was adopted in the prepared slot for casting and retentive features for acrylic were incorporated.

Sprues were then fixed [Fig. 5] and casting was done [Fig. 6]. Finger-like extensions were made all around the periphery of cast metal insert and this was then adapted over the first single thickness of baseplate wax (adapted on the master cast). [Fig. 7] Next a permanent record base with the casting in it was fabricated.

Two acrylic stops were made for stabilization of the casting during dewaxing. [Fig. 8] [While counter flasking the acrylic stops get embedded in the counter flask and hence stabilize the casting]. The wax trial denture base with adapted cast metal insert was processed with high impact heatpolymerized acrylic resin (Trevalon-HI, Dentsply, Germany).

The occlusal vertical dimension and centric relation of the patient was determined using permanent denture base with wax occlusal rims. Mandibular wax rim was then modified to record neutral zone with compound rims [Fig. 9]. Putty index of neutral zone was made and denture teeth were arranged (Acryrock, Ruthenium, Italy).

Trial dentures were then evaluated clinically. After the trial placement was assessed to be satisfactory, trial dentures were processed with high impact heat-polymerized acrylic resin 
(Trevalon-HI, Dentsply, Germany). The prosthesis was retrieved and polished for the denture placement. [Fig. 10]

Discussion-Severe resorption of the mandibular alveolar ridge contributes to instability and discomfort of the conventional acrylic resin denture. Alveolar ridge resorption may be corrected, in part, by various surgical implantation and vestibuloplasty techniques. When these techniques are not feasible, the need to construct a mandibular denture that is strong, stable, and functional can be met by a metal based denture. The weight, design, and inherent strength of such a denture meet the patient's special needs. ${ }^{7}$

\section{REFERENCES:}

1. Grunewald AH. Gold base lower dentures. J Prosthet Dent 1964; 14: 432-41.

2. Kim H, Brewer JD and Monaco E. Internally weighted mandibular denture fabrication using a processed denture base. J Prosthet Dent 2009; 102: 123-125.

3. Wormley JH, Brunton DA. Weighted mandibular dentures. J Prosthet Dent 1974; 32: 101-2.

4. Hurtado AJ. Internally weighted mandibular dentures. J Prosthet Dent 1988; 60: 122-3.

5. Prithviraj D. R, Vishal Singh, Sarvanan Kumar, Shruti D P. Conservative Prosthodontic procedures to improve mandibular stability in an atropic mandibular ridge. J Indian Prosthodont Soc 2008, 8: 4: 178-184.

6. Graser GN. Completed bases for removable dentures. J Prosthet Dent 1978; 39: 232-6.

7. Pasam N, Hallikerimath RB, Gangadhar. Relining a metal denture base: A clinical report. J Indian Prosthodont Soc 2006; 6: 1: 51-53.
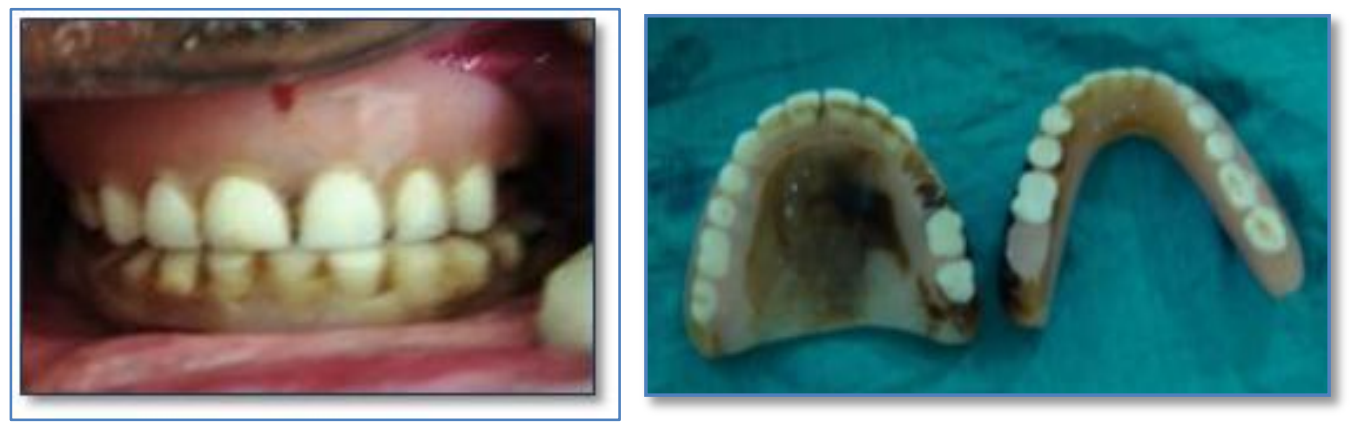

Old dentures of the patient [Fig. 1a, Fig. 1b]

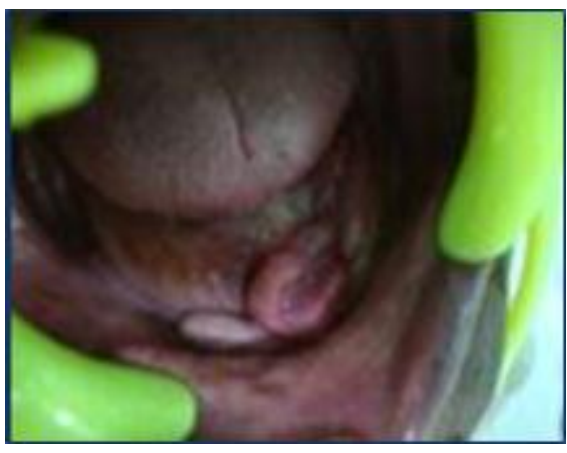

Soft tissue growths [Fig. 2a]

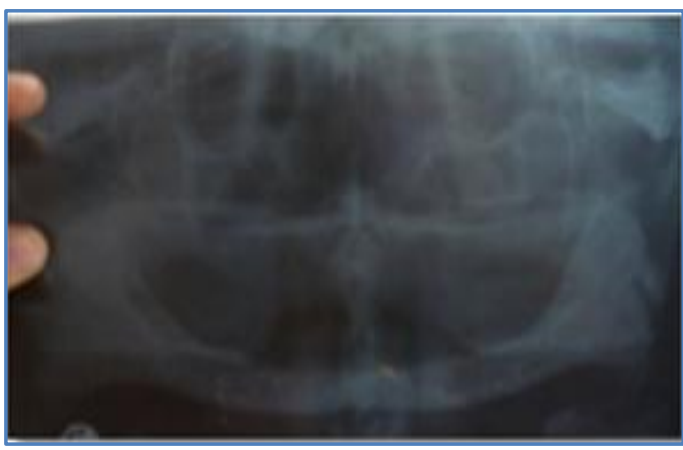

Radiographic assessment [Fig. 2b] 


\section{CASE REPORT}

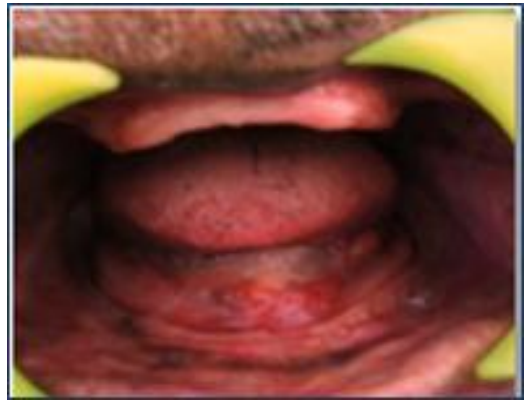

Healed lower ridge [Fig. 2c]

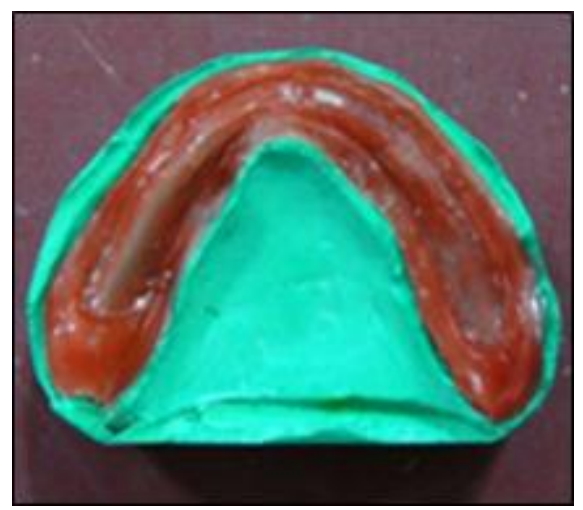

Space for casting [Fig. 4]

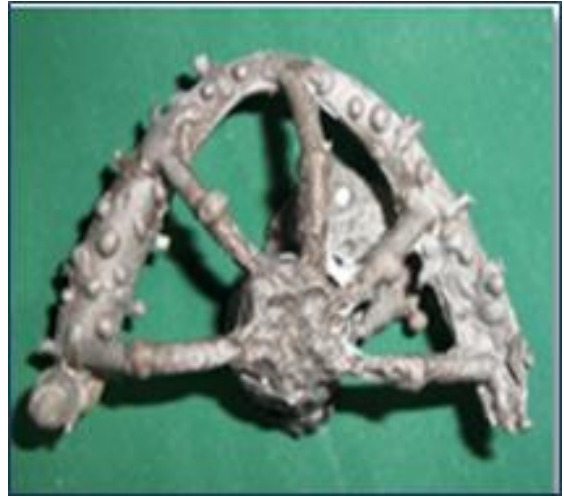

Retrived metal casting [Fig. 6]

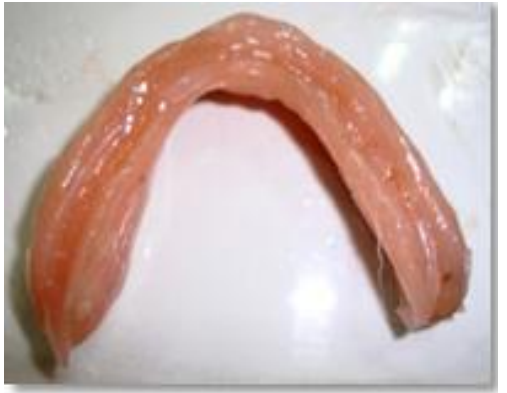

Physiologic impression with soft liner [Fig. 3]

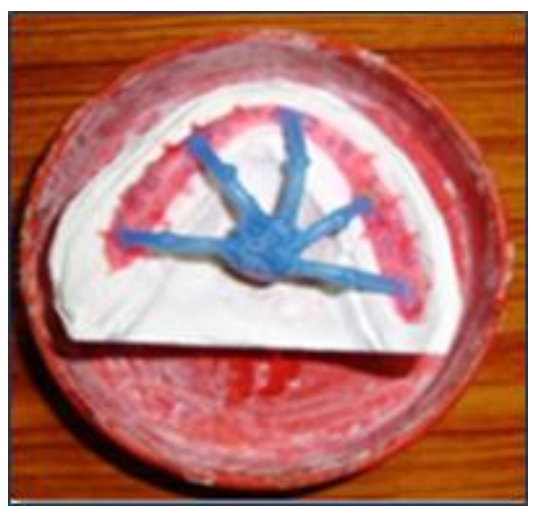

Refractory cast [Fig. 5]

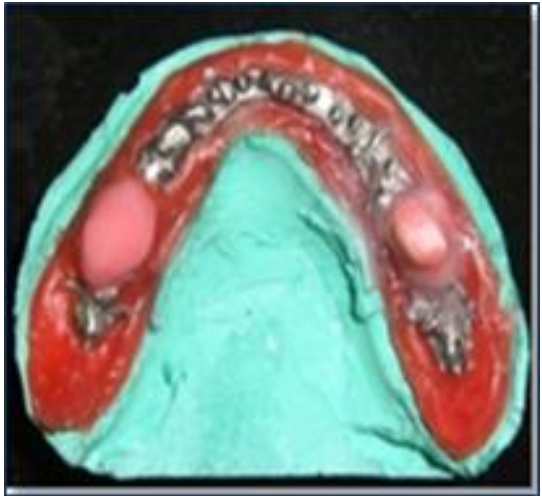

Acrylic stops [Fig. 7] 


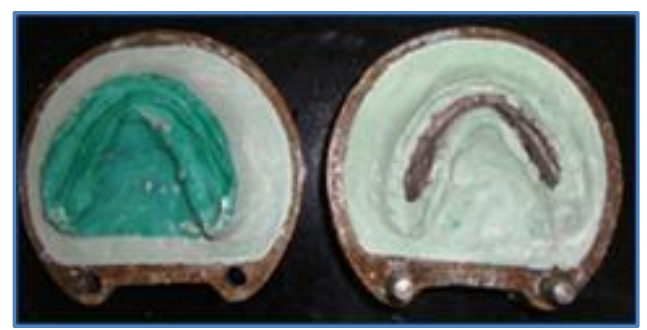

Stabalization of casting [Fig. 8]

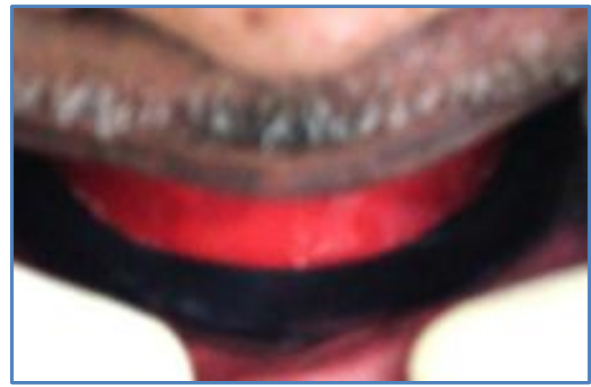

Natural Zone [Fig. 9]

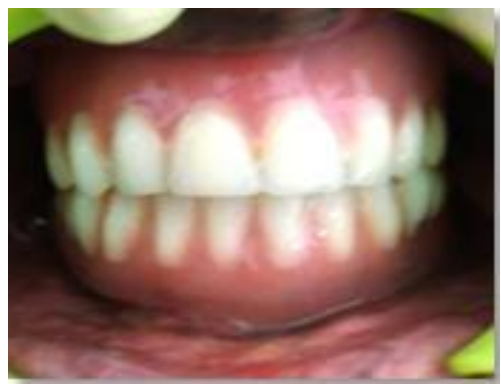

Final Prosthesis [Fig. 10]

\section{AUTHORS:}

1. Puja Hazari

2. Mukesh Yadav

3. Ajay Gaikwad

4. Vandana Singh

5. Kirti Somkuwar

\section{PARTICULARS OF CONTRIBUTORS:}

1. Senior Lecturer, Department of Prosthodontics, People's Dental Academy, Bhanpur, Bhopal, Madhya Pradesh.

2. Senior Lecturer, Department of Prosthodontics, Bhabha College of Dental Sciences, Jatkhedi, Bhopal, Madhya Pradesh.

3. Reader, Department of Prosthodontics, RKDF Dental College \& Research Center, Jatkhedi, Bhopal, Madhya Pradesh.

4. Senior Lecturer, Department of Oral Medicine \& Radiology, Bhabha College of Dental Sciences, Jatkhedi, Bhopal, Madhya Pradesh.

5. Senior Lecturer, Department of Prosthodontics, Rishiraj College of Dental Sciences \& Research Center, Bhopal, Madhya Pradesh.

\section{NAME ADDRESS EMAIL ID OF THE CORRESPONDING AUTHOR:}

Dr. Puja Hazari

HIG/C-14, PCMS Campus,

Bhanpur,

Bhopal-462037, M.P.

Email: hazaripuja@yahoo.com

Date of Submission: 17/08/2014.

Date of Peer Review: 18/08/2014.

Date of Acceptance: 27/08/2014.

Date of Publishing: 04/09/2014. 